Hans-Jürgen Wilhelm • Tobias Kurtz Beziehungsgestaltung

\title{
in der Pflege von Menschen mit Demenz
}

Expertenstandard in der Praxis anwenden
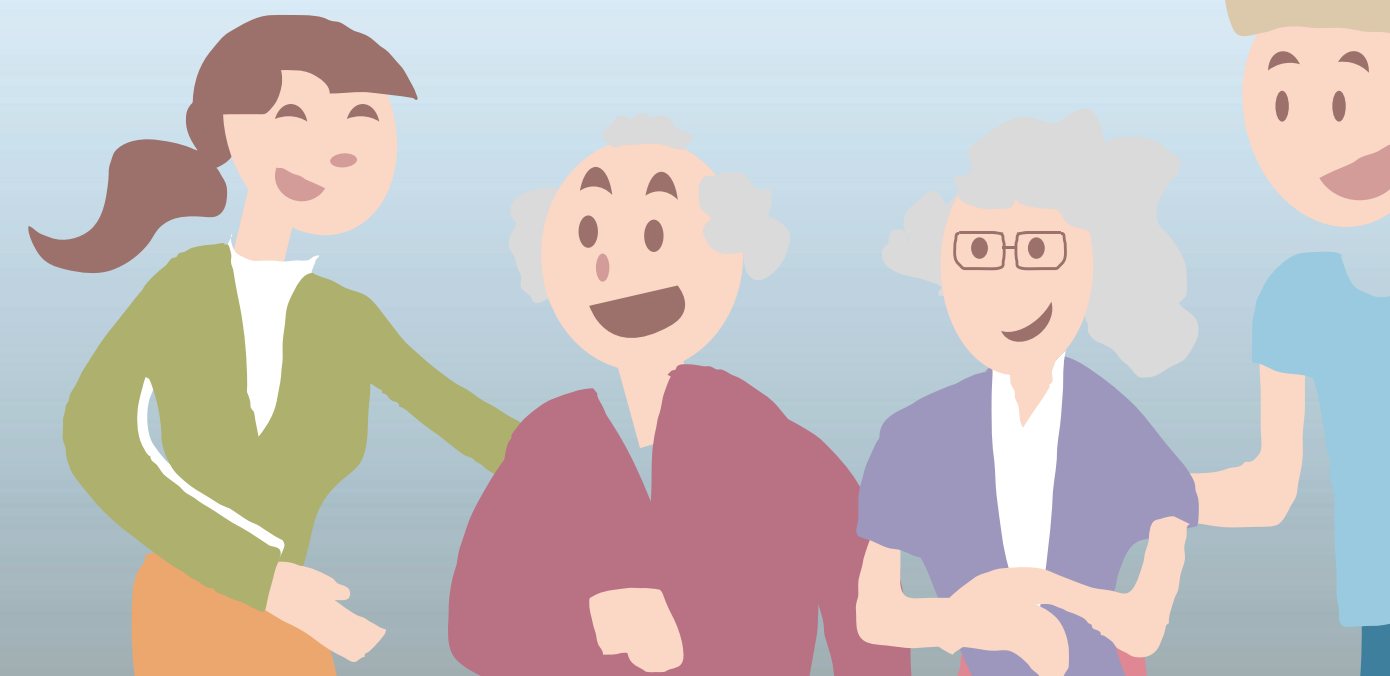

Altenpflege 
Bibliografische Information der Deutschen Nationalbibliothek

Die Deutsche Bibliothek verzeichnet diese Publikation in der Deutschen Nationalbibliografie;

detaillierte bibliografische Daten sind im Internet über http://dnb.d-nb.de abrufbar.

Sämtliche Angaben und Darstellungen in diesem Buch entsprechen dem aktuellen Stand des Wissens und sind bestmöglich aufbereitet.

Der Verlag und der Autor können jedoch trotzdem keine Haftung für Schäden übernehmen, die im Zusammenhang mit Inhalten dieses Buches entstehen.

\section{(c) VINCENTZ NETWORK, Hannover 2020}

Besuchen Sie uns im Internet: www.altenpflege-online.net

Das Werk ist urheberrechtlich geschützt. Jede Verwendung außerhalb der engen Grenzen des Urheberrechtsgesetzes ist ohne Zustimmung des Verlages unzulässig und strafbar.

Dies gilt insbesondere für die Vervielfältigungen, Übersetzungen, Mikroverfilmungen und Einspeicherung und Verarbeitung in elektronischen Systemen.

Die Wiedergabe von Gebrauchsnamen, Warenbezeichnungen und Handelsnamen in diesem Buch berechtigt nicht zu der Annahme, dass solche Namen ohne Weiteres von jedermann benutzt werden dürfen. Vielmehr handelt es sich häufig um geschützte, eingetragene Warenzeichen.

Titelbild: Tobias Kurtz

Illustration: Tobias Kurtz

Druck: Pajo AS, 86703 Sindi, Estland

ISBN 978-3-7486-0356-6 